\title{
A Hybrid Genetic Algorithm Applied to the Transmission Network Expansion Planning Considering Non-conventional Solution Candidates
}

\author{
Jaime Andrés López López \\ Expertos en Mercados XM S.A. E.S.P. - Filial de ISA, \\ Calle 12 Sur No. 18-168, Medellín - Colombia.
}

\author{
Jesús María López Lezama \\ Grupo GIMEL, Departamento de Ingeniería Eléctrica, \\ Universidad de Antioquia Calle 70 No 52-21, \\ Medellín 050010, Colombia.
}

ORCID: 0000-0002-2369-6173

\author{
Nicolás Muñoz Galeano \\ Grupo GIMEL, Departamento de Ingeniería Eléctrica, \\ Universidad de Antioquia Calle 70 No 52-21, \\ Medellín 050010, Colombia.
}

ORCID: 0000-0003-1407-5559

\begin{abstract}
This paper presents a mixed integer nonlinear programming approach for solving The Transmission Network Expansion Planning (TNEP) problem through a hybrid genetic algorithm. The TNEP determines the set of new circuits required in an electrical power system to attend future energy demand at a minimum cost. In its classic version, it only considers as candidate solutions the addition of new lines and transformers. The main contribution of this work is the inclusion of nonconventional candidate solutions which include are repowering of existing circuits and shunt compensation. Also an AC modeling of the network that allows obtaining more realistic results has been considered. Results on the IEEE 24bus test system show the applicability and effectiveness of the proposed approach.
\end{abstract}

Keywords: Black start, power systems, start-up sequence, optimization.

\section{INTRODUCTION}

The TNEP problem consists of determining the new elements that must be added to the power system to meet the future demand at the lowest possible cost. The classic version of the TNEP problem only considers the addition of new circuits to the system (lines and transformers). However, the acquisition of right of ways or corridors for new transmission lines is increasingly difficult and expensive, mainly due to environmental restrictions and social problems. Within this context, the implementation of unconventional solution candidates to the TNEP such as circuit repowering and capacitor placement has become attractive to power system planners.

Numerous studies have been reported in the technical literature regarding the TNEP problem. A quick search in databases reveals several thousand of papers published on the subject since 1970 . The main reason for this high number of publications is due to the variations in the models and optimization methods implemented for the TNEP solution.
The closest representation of TNEP corresponds to a Mixed Integer Nonlinear Programming problem that involves nonlinear functions, as well as continuous and integer variables. Due to its combinatorial nature, the TNEP is a highly complex mathematical problem. Simplifications of the TNEP problem lead to models that can be approached using classical mathematical programming (Linear Programming, Non-Linear Programming, Mixed Integer Linear Programming, Quadratic Programming and Dynamic Programming). The TNEP problem can be represented by the transport model, DC model, hybrid model, disjunctive model and AC model [1] - [4].

The solution methods applied to the TNEP problem can be classified into three large groups: methods based on classical mathematical programming, heuristic techniques and metaheuristic techniques. Within the latter, the most widely used are Genetic Algorithms (GA) [5] - [7], Taboo Search (TS) [8], and Particle Swarm Optimization (PSO) [9]. Although a bunch of methodologies have been proposed in the technical literature to address the TNEP problem, few studies consider the possibility of incorporating unconventional solution candidates. In this regard, there are studies that have separately considered the inclusion of series compensation [10], shunt compensation [11], repowering and reconfiguration of existing circuits [12] - [14], change in voltage levels and technology of conductors in certain circuits [15]. Furthermore, another aspect that has gained relevance in the evolution of the models is the integration of the previously mentioned solution techniques with new methodologies, to consider aspects of electricity markets [16], financial and economic evaluation [17], regulatory mechanisms [18], smart grids [19], generation with renewable resources [20], and demand response [21] among others.

In this sense, the main contribution of this work is the modeling of unconventional solution candidates to the TNEP problem which includes repowering of existing networks and location of compensation elements considering an AC model of the transmission network. The results obtained when including this type of candidate solutions show that it is 
possible to explore a broader set of solutions and, eventually, contribute with lower-cost expansion options for the TNEP solution. The solution method is a hybrid GA-TS implemented in the IEEE 24-bus test systems that proved to be effective for solving the TNEP problem.

\section{MATHEMATICAL MODELING}

The compact mathematical formulation of the TNEP is given by equations (1) - (9). In this case, the AC model of the transmission network is used. A detailed description of the model can be found in [4].

$$
\operatorname{Min} \mathrm{v}=\mathrm{c}^{\mathrm{T}} \mathrm{n}
$$

Sujeto a:

$$
\begin{gathered}
P(V, \theta, n)-P_{G}+P_{D}=0 \\
Q(V, \theta, n)-Q_{G}+Q_{D}=0 \\
\underline{P}_{G} \leq P_{G} \leq \bar{P}_{G} \\
\underline{Q}_{G} \leq Q_{G} \leq \bar{Q}_{G} \\
\underline{V} \leq V \leq \bar{V} \\
\left(N+N^{0}\right) S^{\text {from }} \leq\left(N+N^{0}\right) \bar{S} \\
\left(N+N^{0}\right) S^{\text {to }} \leq\left(N+N^{0}\right) \bar{S} \\
0 \leq n \leq \bar{n}
\end{gathered}
$$

$\mathrm{n}$ integer and $\theta$ unbounded

Where $\mathrm{c}$ and $\mathrm{n}$ represent the vector of circuit costs that can be added to the network and the vector of added circuits, respectively; $\mathrm{N}$ and $\mathrm{N}^{0}$ are diagonal matrices that contain the vector $\mathrm{n}$ and the existing circuits in the base configuration, respectively; $\mathrm{v}$ is the investment cost due to the addition of circuits to the networks; $\overline{\mathrm{n}}$ is the vector that contains the maximum number of circuits that can be added; $\theta$ is the vector of the phase angle. $\mathrm{P}_{\mathrm{G}}$ and $\mathrm{Q}_{\mathrm{G}}$ are the vectors of generated active and reactive power. $P_{D}$ and $Q_{D}$ are the vectors of the active and reactive power demand; $\mathrm{V}$ is the vector of voltage magnitudes; $\overline{\mathrm{P}}_{\mathrm{G}}, \overline{\mathrm{Q}}_{\mathrm{G}}$ and $\overline{\mathrm{V}}$ are the maximum limits (represented as vectors) of active and reactive power generation as well as voltage magnitudes; similarly $\underline{P}_{G}, \underline{Q}_{G}$ and $\mathrm{V}$ represent the minimum limits of the same variables. $S^{\text {from }}, S^{\text {to }}$ and $\bar{S}$ are the vectors of the apparent power flow in the branches, in both terminals and their limits.
The elements of vectors $P(V, \theta, n)$ and $Q(V, \theta, n)$ are given by equations (10) and (11), respectively.

$$
\begin{aligned}
& P_{i}(V, \theta, n)=V_{i} \sum_{j \in N} V_{j}\left[G_{i j}(n) \cos \theta_{i j}+B_{i j}(n) \sin \theta_{i j}\right] \\
& Q_{i}(V, \theta, n)=V_{i} \sum_{j \in N} V_{j}\left[G_{i j}(n) \sin \theta_{i j}-B_{i j}(n) \cos \theta_{i j}\right]
\end{aligned}
$$

Where $i, j \in N$ are indices representing the buses of the system and $\mathrm{N}$ is the set of all buses; $\mathrm{i}-\mathrm{j}$ represent the circuit between bus $i$ and $j \cdot \theta_{i j}=\theta_{i}-\theta_{j}$ represents the angular difference between bus $i$ and $j$. The details of obtaining elements of the admittance matrix ( $\mathrm{G}$ and $\mathrm{B}$ ) can be consulted in [4].

\section{METHODOLOGY}

A GA hybridized with a TS was developed to solve the TNEP problem. The details of the proposed methodology are presented below.

\section{III.I Codification}

Figure 1 illustrates the 6-bus Garver system, while Figure 2 depicts a candidate solution for this power system. The candidate solution is an array which size is the number of corridors plus the number of buses available for compensation and the number of reconfiguration options.

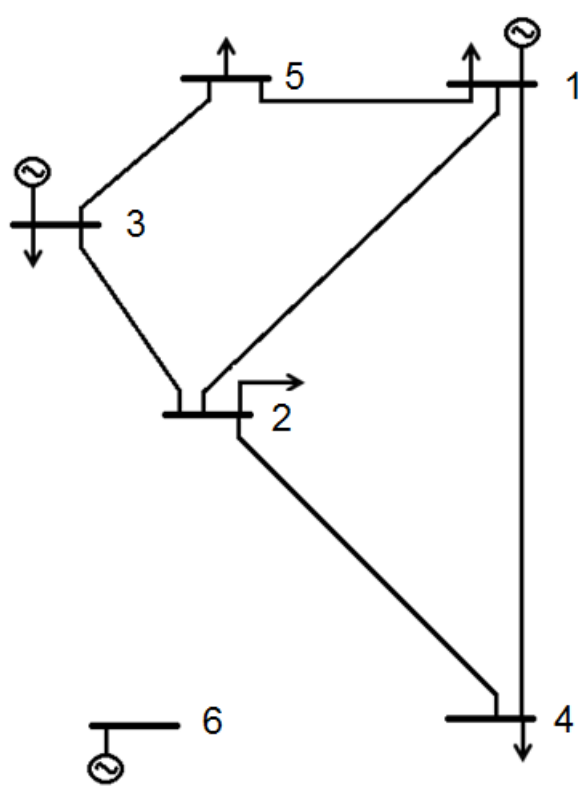

Figure 1. Topology of the 6-bus Garver system 


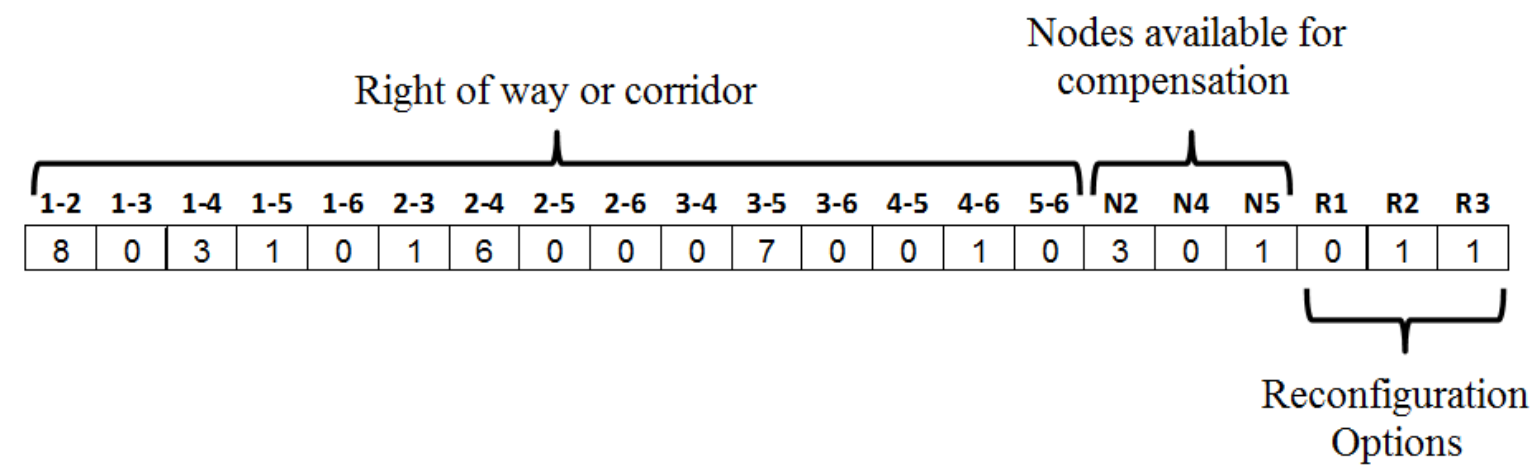

Figure 2. Illustration of a solution candidate for the 6-bus Garver system

Rights of ways or corridors:

- LNmax, indicates the maximum number of lines per corridor in parallel.

$(\mathrm{LNmax}+1)$, indicates the repowering of the existing circuits (base topology).

- (LNmax + 2), indicates a capacitive series compensation location.

- (LNmax + 3), indicates an inductive series compensation.

Shunt compensation:

- This section of the candidate solution comprises the nodes available for shunt compensation. The bit indicates the number of steps in the bank. This can range from a negative value (inductive compensation), to a positive value (capacitive compensation).

\section{Reconfiguration options}

- Network reconfiguration options are located in the last section of the candidate solution. Such options have previously been evaluated and considered as a possible expansion option. When the bit goes from 0 to 1 , it indicates that the corresponding reconfiguration option is active on the network.
The Garver system allows a maximum of 5 lines per corridor. According to the aforementioned codification, Figure 2 indicates an inductive series compensation in corridor 1-2, two new circuits for corridor 1-4, repowering of the existing line in corridor 2- 4, a capacitive series compensation in corridor 3-5, a new line in corridor 4-6, a 3-step capacitive compensation at node 2 , a 1-step capacitive compensation at node 5 and the activation of reconfiguration options 2 and 3 .

It is worth to mention that the objective function is the installation costs of all the aforementioned elements in the network.

\section{III.II Tabu hybridation}

A hybrid GA-Tabu Seach is proposed to find high-quality solutions for the TNEP problem. In this case, the Tabu search replaces the mutation state of the GA. The Tabu Search incorporates a short-term memory, which stores neighbors of the current candidate solution so as not to repeat them in certain stages of the process, unless a specific aspiration criterion is met. In this case, two Tabu Lists (TL) were used: one for the section of the individual that corresponds to the corridors, and another one for the compensation in derivation.

Figure 3 illustrates how the TL for corridors is constructed. It stores each of the bits that are visited until a MaxTL size. When a bit is visited, it goes through all the possible values that it can take and the one that generates the best objective function for the individual is identified. The purpose of this $\mathrm{TL}$ is to remember the bits visited and not to repeat them while the process is complete.

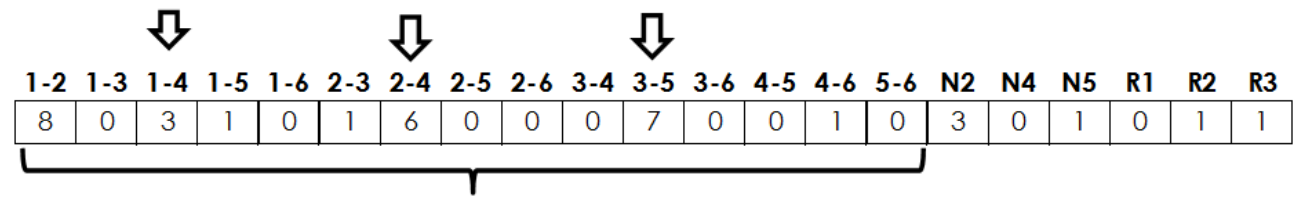

Corridors

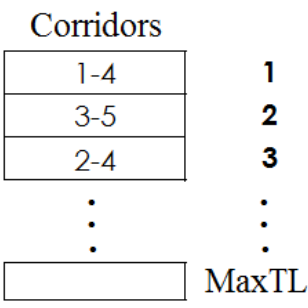

Figure 3. TL for corridors. 


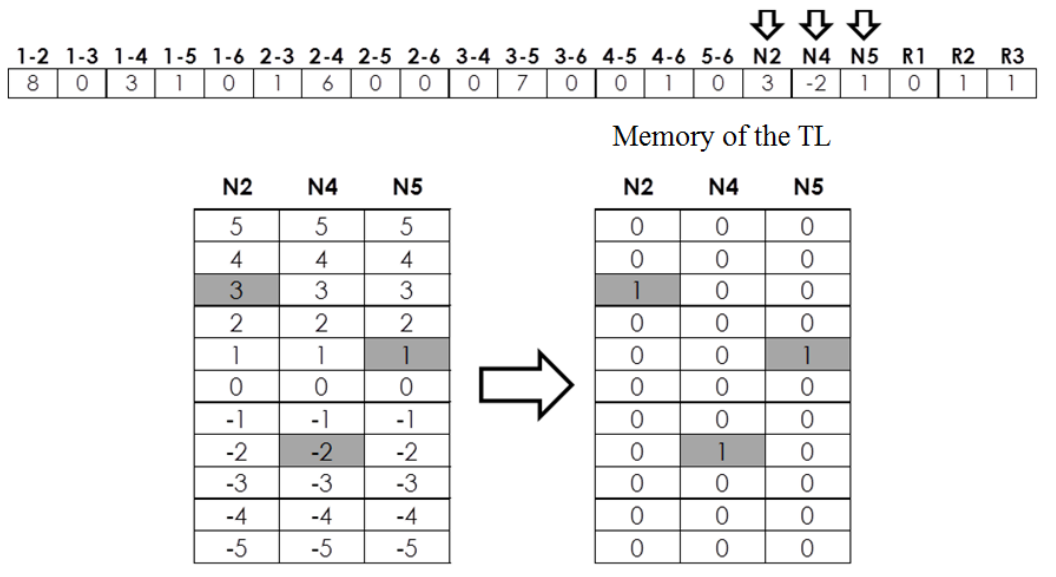

Figure 4. TL for shunt compensation

The construction of the TL for shunt compensation is illustrated in Figure 4. This shows all possible values that the bits corresponding to the nodes established for the shunt compensation location can take. In this case, the TL is a binary array, as many possible values are visited the TL is restricted to a maximum size.

A TL for reconfiguration was not considered. The mutation process is randomly performed considering one of three options: 1) new lines or corridors, 2) shunt compensation allocation and 3 ) reconfiguration.

Figure 5 depicts the flowchart of the proposed methodology. It starts with a feasible candidate solution or individual, followed by the construction of an initial population based on said individual. Then tournament selection and recombination are performed. The best individual goes to the mutation state, which in this case is the TS. The best individual obtained from the TS is compared with the current incumbent and replaces it if it is better.

After verifying the best solution, a process is added in which the number of times that the same value of the incumbent has been repeated " $p$ " generations is verified. If " $p$ " is completed, an initial population is generated again as indicated in the diagram. This process allows that when the algorithm detects that its initial population is homogenizing (possibly converging to a local optimum), the possible solutions for TNEP are diversified through a new population.

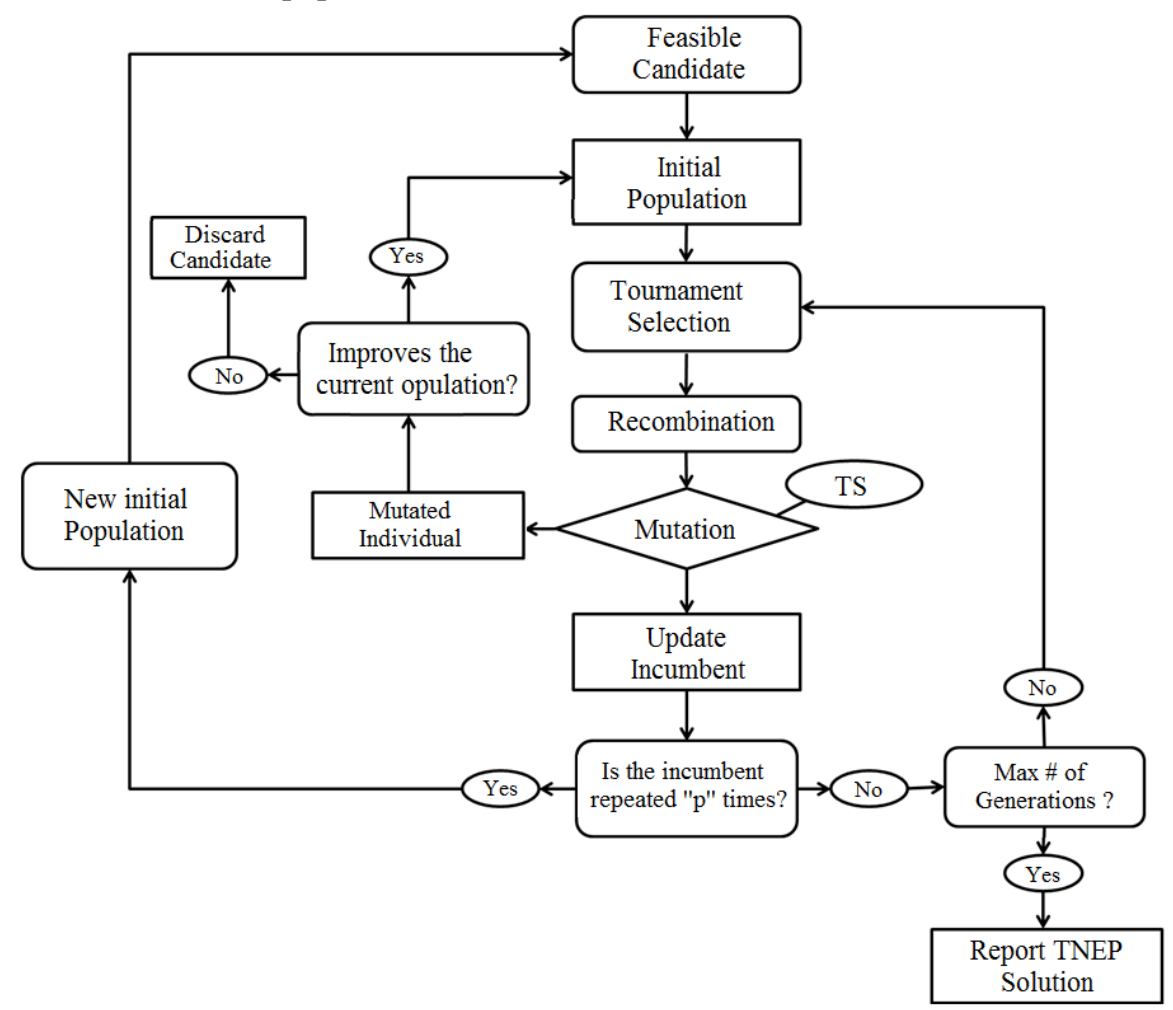

Figure 5. Flowchart of the proposed hybrid GA 
International Journal of Engineering Research and Technology. ISSN 0974-3154, Volume 13, Number 11 (2020), pp. 3303-3309

(C) International Research Publication House. https://dx.doi.org/10.37624/IJERT/13.11.2020.3303-3309

\begin{tabular}{|c|c|c|c|c|c|c|c|c|c|c|c|c|c|c|c|}
\hline $1-2$ & $1-3$ & $1-5$ & $1-8$ & $2-4$ & 2.6 & $2-8$ & 3.9 & $3-24$ & 4.9 & $5-10$ & 6.7 & $6-10$ & $7-8$ & $8-9$ & $8-10$ \\
\hline 1 & 1 & 1 & 0 & 7 & l & 0 & 1 & 5 & 1 & 1 & 0 & 3 & 4 & 1 & 1 \\
\hline $9-11$ & 9.12 & $10-11$ & $10-12$ & $11-13$ & $11-14$ & $12-13$ & $12-23$ & $13-14$ & 13.23 & $14-16$ & $14-23$ & $15-16$ & 15.21 & $15-24$ & $16-17$ \\
\hline 5 & 1 & 1 & 1 & 4 & 1 & 1 & 1 & 0 & 1 & 1 & 0 & 1 & 2 & 1 & 1 \\
\hline $16-19$ & $16-23$ & $17-18$ & $17-22$ & $18-21$ & $19-20$ & $19-23$ & $20-23$ & $21-22$ & N3 & N8 & N10 & 111 & R2 & R3 & R4 \\
\hline 1 & 0 & 1 & 1 & 2 & 2 & 0 & 2 & 1 & 5 & 0 & 0 & 0 & 0 & 0 & 0 \\
\hline
\end{tabular}

Figure 6. Result for IEEE 24-bus test system

\section{TESTS AND RESULTS}

To show the applicability of the proposed approach several tests were performed with the IEEE 24 bus test system. Considering competitive cost for non-conventional solution candidates as indicated in [22] the GA obtains the solution illustrated in Figure 6, with a cost of US\$108 x $10^{6}$.

Figure 7 illustrates the solution implemented in the IEEE 24bus test system. This indicates the repowering of the existing circuits in corridors 7-8 and 11-13, the addition of 2 circuits in corridor 6-10, capacitive series offsets in corridors 3-24 and 911 , and the location of a capacitive shunt compensation at node 3 of 5 steps.

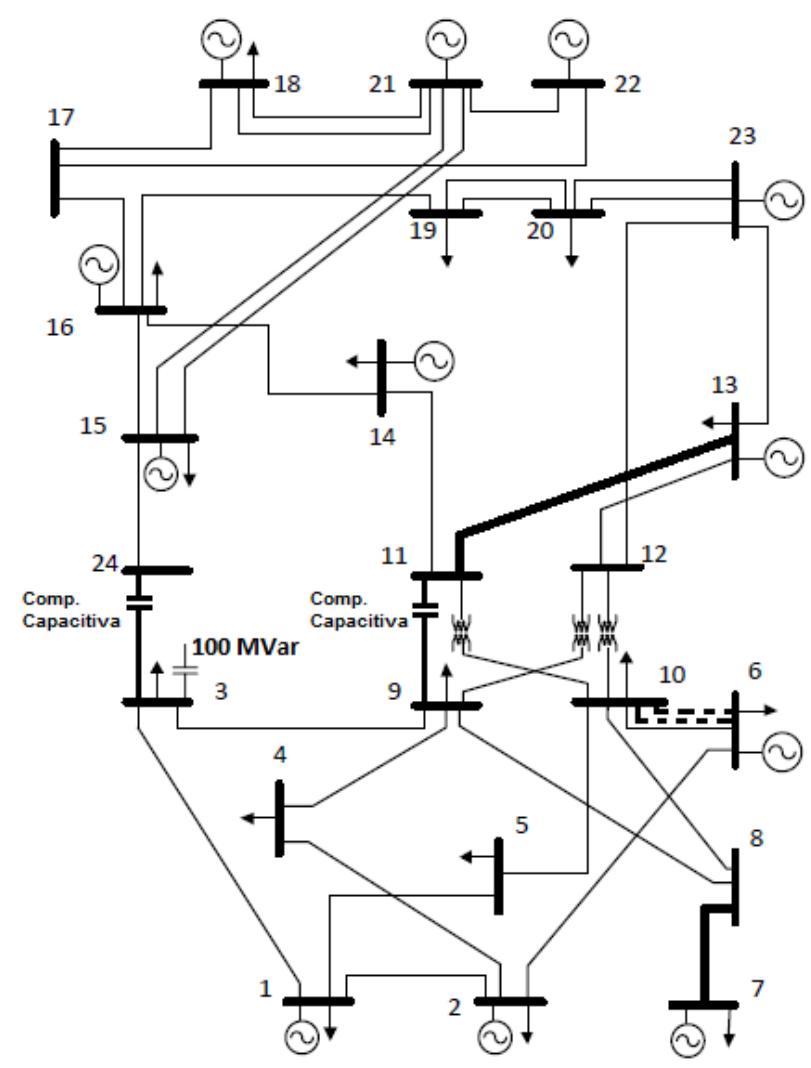

Figure 7. Representation of the solution obtained with the IEEE 24-bus test system considering competitive costs of unconventional candidate solutions.

Considering a higher price for unconventional candidates as presented in [22], the GA obtains the solution presented in
Figure 8 , at a cost of US $\$ 319 \times 10^{6}$. Figure 8 illustrates the solution implemented. This indicates the addition of two circuits in corridor $6-10$, and the addition of a circuit in corridors 1-3, 3-24, 7-8, 9-11, 10-11 and 11-13.

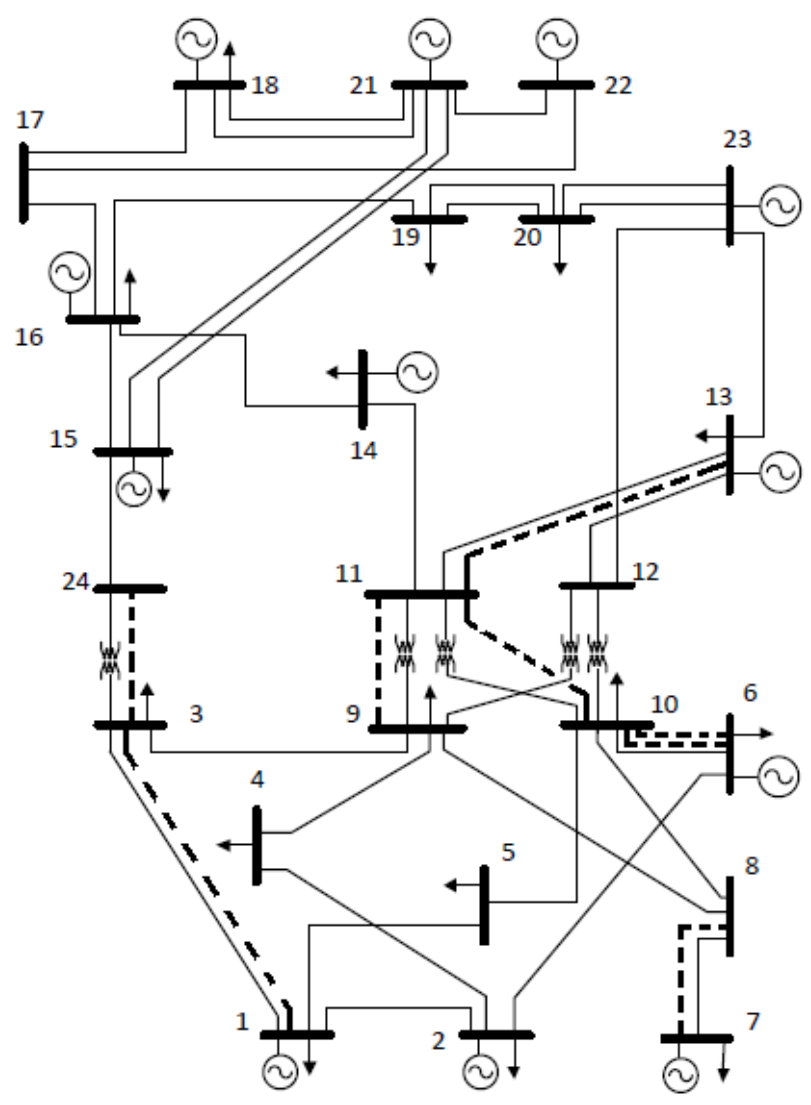

Figure 8. Representation of the solution obtained considering a high cost for unconventional solution candidates.

Figure 9 presents a possible TNEP solution that considers the reconfiguration of existing circuits as an unconventional expansion candidate. The cost associated with this solution is US $\$ 117 \times \times 10^{6}$. This indicates the repowering of the existing circuits in corridors $7-8$ and 11-13, the addition of 2 circuits in corridor 6-10, capacitive series compensations in corridors 3-24 and 9-11, the location of a compensation in capacitive bypass in node 3 of 5 steps and finally the reconfiguration of the existing circuit in corridor 4-9 with node 5 (reconfiguration option 3 ), generating a new circuit for corridors 4-5 and 9-5. 


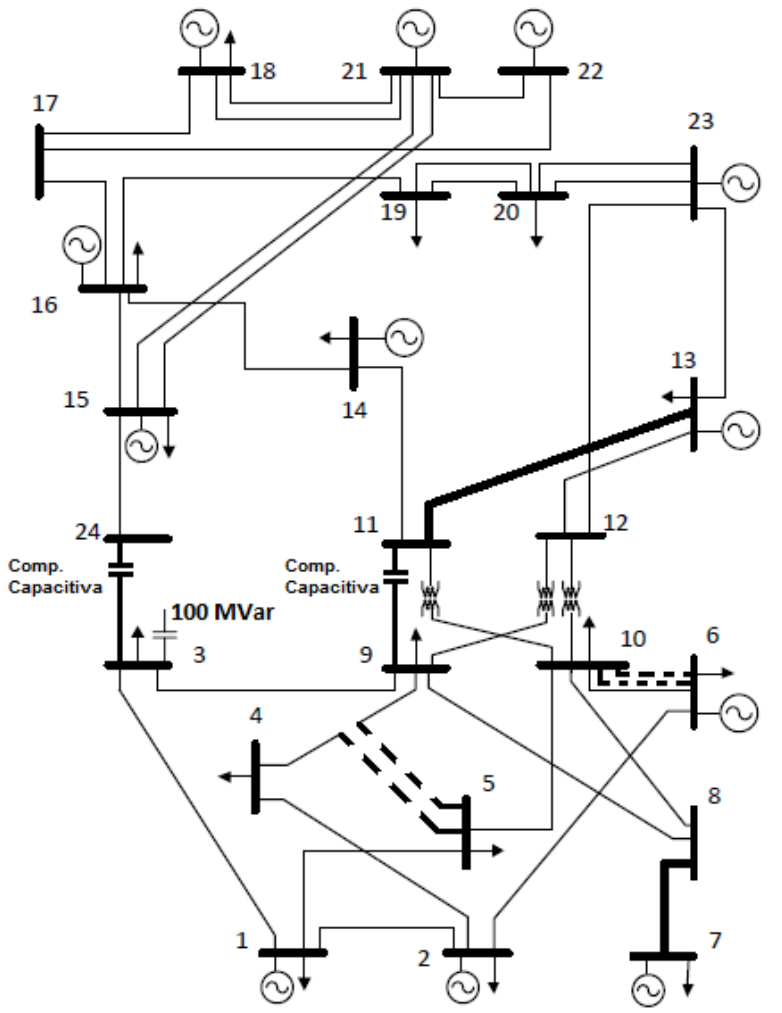

Figure 9. Representation of a solution considering reconfiguration within the expansion plan.

\section{CONCLUSIONS}

This paper presented a hybrid metaheuristic approach to solve the TNEP problem. The main contribution of this work is the introduction of unconventional solution candidates, which includes the repowering and reconfiguration of existing circuits, as well as optimal location of series and shunt compensations. Furthermore, an AC model of the network was implemented, which allows a closer representation of the real phenomena under study.

The inclusion of unconventional solution candidates to the TNEP allows exploring a larger set of possible solutions and find new expansion alternatives that involve lower costs, compared to those obtained by considering only the classic candidates of the TNEP. The proposed hybrid GA proved to be effective in finding high-quality solution to the TNEP problem. The hybrid GA requires a complex implementation; nevertheless, this fact is compensated by its advantages that include fast convergence and achieving high-quality solutions.

\section{Acknowledgements}

The authors gratefully acknowledge the financial support provided by the Colombia Scientific Program within the framework of the call Ecosistema Científico (Contract No. FP44842- 218-2018). Likewise, Universidad de Antioquia (Colombia) is acknowledged for the financial support through the Sostenibilidad program.

\section{REFERENCES}

[1] L. Garver, "Transmission Network Estimation Using Linear Programming," IEEE Trans. Power Appar. Syst., vol. PAS-89, no. 7, pp. 1688-1697, Sep. 1970.

[2] L. Bahiense, G. C. Oliveira, M. Pereira, and S. Granville, "A mixed integer disjunctive model for transmission network expansion," IEEE Trans. Power Syst., vol. 16, no. 3, pp. 560-565, 2001.

[3] R. Romero, A. Monticelli, A. Garcia, and S. Haffner, "Test systems and mathematical models for transmission network expansion planning," IEEE Gener. Transm. Distrib., vol. 149, no. 1, pp. 27-36, 2002.

[4] M. J. Rider, A. V Garcia, and R. Romero, "Power system transmission network expansion planning using AC model," IET Gener. Transm. Distrib., vol. 1, no. 5, pp. 731-742, 2007.

[5] L. A. Gallego, M. J. Rider, R. Romero, and A. V Garcia, "A Specialized Genetic Algorithm to Solve the Short Term Transmission Network Expansion Planning," IEEE Bucharest Power Tech Conf. Bucharest, Rom., pp. 1-7, 2009.

[6] I. Alhamrouni, A. Khairuddin, A. K. Ferdavani, and M. Salem, "Transmission expansion planning using AC-based differential evolution algorithm," IET Gener. Transm. Distrib., vol. 8, no. 10, pp. 16371644, 2014.

[7] A. H. Domínguez, A. E. Zuluaga, and R. Gallego, "Un método híbrido de optimización para el Planeamiento de la transmisión considerando diferentes niveles de tensión," Rev. Fac. Ing. Univ. Antioquia, pp. 154-164, 2012.

[8] A. Escobar, E. Toro, and R. Gallego, "Encadenamiento de trayectorias aplicado al problema del planeamiento de la transmisión," Rev. Fac. Ing. Univ. Antioquia, vol. 53, pp. 185-195, 2010.

[9] D. Kavitha and K. S. Swarup, "Transmission Expansion Planning using LP-Based Particle Swarm Optimization," in in Proc. of the 2006 IEEE Power Conference, New Delhi, India, 2006, pp. 1-5.

[10] M. Rahmani et al., "Multistage Transmission Expansion Planning Considering Fixed Series Compensation Allocation," IEEE Trans. Power Syst., vol. 28, no. 4, pp. 3795-3805, 2013.

[11] T. S. P. and C. C.A., "Expansion planning for smart transmission grids using AC model and shunt compensation," Gener. Transm. Distrib. IET, vol. 8, no. 5, pp. 966-975, 2014.

[12] E. de T. E. S. A. (ETESA), "Informe de proyectos al 31 de diciembre de 2011," Gerencia de Proyectos, Panamá. 2011.

[13] A. S. A. O. y E. Torres, "Estudio de repotenciación de las líneas de transmisión Itaipú - Margen Derecha en 
$500 \mathrm{kV}$ con conductores Termoresistentes," Décimo Tercer Encuentro Regional Iberoamericano de CIGRÉ, Puerto Iguazú. pp. 1-6, 2009.

[14] C. de O. E. del S. I. N. (COES), "Informe DP-012012: Propuesta de la Actualización del Plan de Transmisión 2013 - 2022,” 2012.

[15] A. H. Domínguez, A. E. Z, and R. A. Gallego, "Transmission Expansion Planning Considering Conductor Proposals with Different Wire Size and Technology," Transm. Distrib. Conf. Expo. - Lat. Am. (PES T\&D-LA), 2014.

[16] R. Fang and D. J. Hill, "A New Strategy for Transmission Expansion in Competitive Electricity Markets," IEEE Trans. Power Syst., vol. 18, no. 1, pp. 374-380, 2006.

[17] E. E. Sauma and S. S. Oren, "Economic Criteria for Planning Transmission Investment in Restructured Electricity Markets," IEEE Trans. Power Syst., vol. 22, no. 4, pp. 1394-1405, Nov. 2007.

[18] P. R. Gribik, D. Shirmohammadi, J. S. Graves, and J. G. Kritikson, "Transmission Rights and Transmission Expansions," IEEE Trans. Power Syst., vol. 20, no. 4, pp. 1728-1737, Nov. 2005.

[19] S. P. Torres and C. A. Castro, "Expansion planning for smart transmission grids using AC model and shunt compensation," IET Gener. Transm. Distrib., vol. 8, no. 5, pp. 966-975, 2014.

[20] S. Majumder, R. M. Shereef, and S. A. Khaparde, "Two-stage algorithm for efficient transmission expansion planning with renewable energy resources," IET Renew. Power Gener., vol. 11, no. 3, pp. 320329, 2017.

[21] Ö. Özdemir, F. D. Munoz, J. L. Ho, S. Member, and B. F. Hobbs, "Economic Analysis of Transmission Expansion Planning With Price-Responsive Demand and Quadratic Losses by Successive LP," IEEE Trans. Power Syst., vol. 31, no. 2, pp. 1096-1107, 2016.

[22] J.A. López Lopez, "Planeamiento de la Expansion de redes de transmision considerando repotenciación, reconfiguracion de circuitos existentes y ubicación de compensaciones en serie y derivación," Mater thesis, Universidad de Antioquia 2017. 